Im „Journal Club“ werden Originalarbeiten aus der internationalen Fachliteratur referiert und kommentiert.

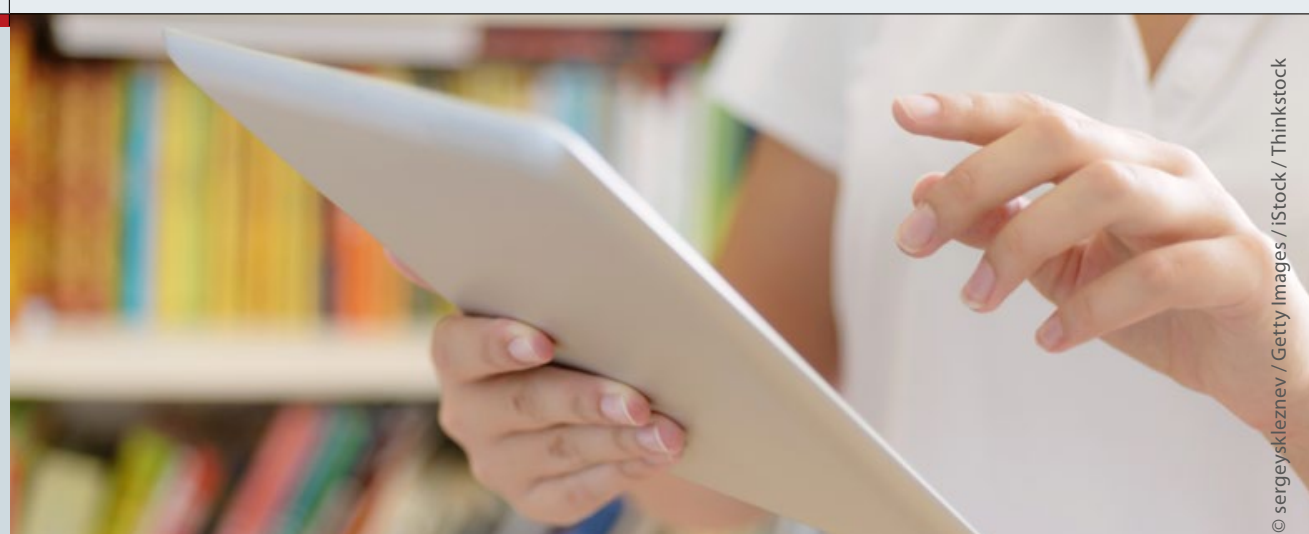

\section{Fünf-Punkte-Score deckt Op.-Risiko bei Senioren auf}

\author{
Ein einfacher Fünf-Punkte-Score hilft beim präoperativen Risiko-Assessment \\ geriatrischer Patienten. Bei der Vorhersage der Ein-Jahres-Mortalität nach \\ einer Not-Operation fanden US-Forscher erstaunlich gute Trefferquoten.
}

D as Sterberisiko nach einer Notoperation ist bei geriatrischen Patienten noch im gesamten ersten Jahr deutlich erhöht; dies hat ein Team aus dem Brigham and Women's Hospital in Boston bereits in einer früheren Arbeit belegt. Nun wollten die Forscher untersuchen, inwieweit präoperativ zu erhebende Faktoren über die postoperative Mortalität Auskunft geben können. Dazu schlossen Dr. Olubode A. Olufajo und Kollegen retrospektiv alle

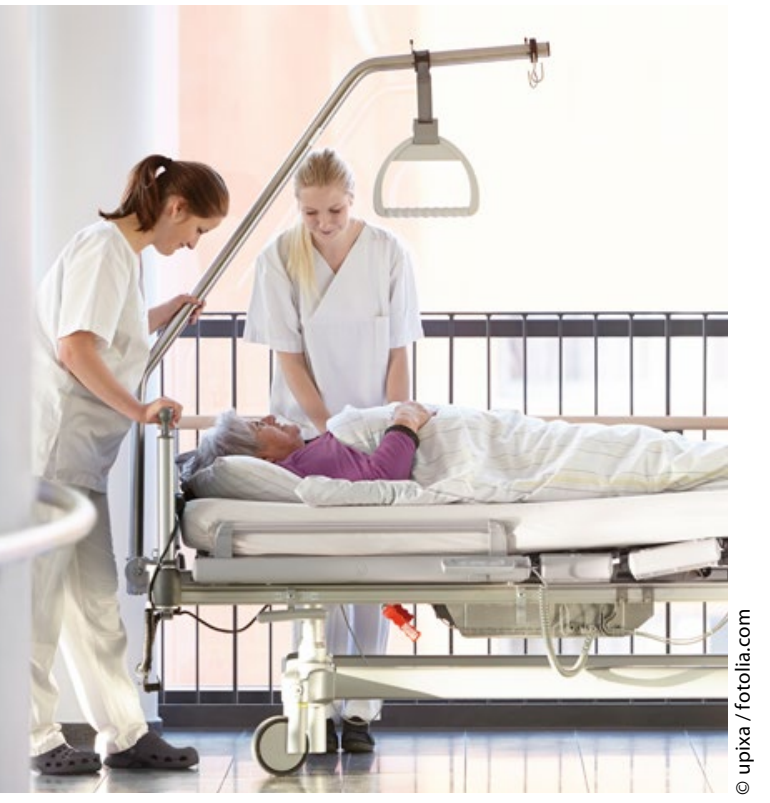

Gibt es einen Score, der hilft, diejenigen Patienten zu identifizieren, die durch eine Op. am meisten gefährdet sind?
Patienten im Alter von 70 Jahren und darüber ein, die zwischen 2006 und 2011 in ihrer Lehrklinik wegen eines abdominalchirurgischen Notfalls operiert worden waren. Als Notoperation waren Eingriffe definiert, die innerhalb von vier Stunden nach der Klinikeinweisung vorgenommen worden waren.

Wie die Autoren berichten, gelangten 421 solcher Operationen, die im Studienzeitraum an 390 Patienten vorgenommen worden waren, zur Auswertung. In erster Linie handelte es sich um Darmresektionen (40\%) und Cholezystektomien (18\%). 77\% aller Eingriffe wurden im Nachhinein als „schwer“ („major“) eingestuft. Die 30-Tages-Mortalität lag bei insgesamt $16,2 \%$. Nach einem Jahr war die Sterblichkeit auf 32,5\% gestiegen.

\section{GEM-Score punktet mit hoher Trefferquote}

Fünf Variablen waren laut Olufajo et al. mit einer erhöhten Ein-Jahres-Mortalität verknüpft: akute Niereninsuffizienz, ASA-Klasse $\geq$ IV, BMI $<18,5$, CharlsonScore $\geq 4$ und Serum-Albumin $<3,5 \mathrm{mg} /$ dl. Auch die Schwere des Eingriffs hatte sich als signifikanter Einflussfaktor herausgestellt; da sich dieser jedoch präoperativ schwer bestimmen lässt, wurde er von den Forschern nicht für den Score berücksichtigt.

Der daraus resultierende Fünf-Punkte-Score, von den Forschern als GEM(Geriatric Emergency Surgery Mortali-
ty)-Score bezeichnet, punktete mit einer vergleichsweise sehr guten Trefferquote: Von 31 Patienten mit der präoperativ besten Punktzahl, nämlich 0, war ein Jahr nach der Not-Op. kein einziger verstorben. Diejenigen mit den schlechtesten Werten (7 oder 8) waren ein Jahr postoperativ alle gestorben. Im Bereich 0 bis 1 Punkt lag die Ein-Jahres-Mortalität zwischen 0 und $7 \%$, bei 2 bis 5 Punkten zwischen 32 und $68 \%$ und bei 6 bis 8 Punkten zwischen 94 und 100\%.

Nach Olufajo et al. waren schlechte Nierenwerte (Serumkreatinin $\geq 0,3 \mathrm{mg}$ / dl oder ein Anstieg um 50\% oder mehr innerhalb von $24 \mathrm{~h}$ ), ASA-Klasse und Untergewicht die wichtigsten Prädiktoren für die längerfristige Mortalität. Der weit verbreitete Charlson-Komorbiditäts-Index schnitt im Vergleich dazu schlechter ab: „Der CCI für sich genommen ist möglicherweise kein adäquates Mittel zur Risikostratifizierung“, so die Autoren. Der neue Score war nach Angaben der Autoren auch dem ASA-Score als alleinigem Tool überlegen. $\mathrm{Ob}$ sich der GEM-Score in der breiten Anwendung bewähren wird, lässt sich derzeit noch nicht sagen; zunächst muss er nun in anderen Settings überprüft werden. Nach Olufajo und Kollegen birgt er zumindest das Potenzial, diejenigen Patienten $\mathrm{zu}$ identifizieren, die durch eine Op. am meisten gefährdet sind. Diese könne man, sofern es sich nicht um einen unmittelbar lebensnotwendigen Eingriff handle, möglicherweise alternativen Maßnahmen zuführen.

(eo)

Olufajo OA et al. Preoperative Assessment of Surgical Risk: Creation of a Scoring Tool to Estimate One-Year Mortality after Emergency Abdominal Surgery in the Elderly Patient. Am J Surg 2016; online 3. September; doi: 10.1016/j. amjsurg.2016.08.007 